\title{
Family Quality of Life for Families in Early Intervention Centers in Jordan
}

\author{
Amani Mohamed Mahmoud \\ Middle East University, Jordan
}

\begin{abstract}
This research aimed at finding out the satisfaction degree of families of children with special needs, about the quality of family services provided in early intervention centers in Jordan. The sample consisted of (100) families of children with special needs. The descriptive methodology was used. The questionnaire was used to collect data. It consisted of five main dimensions. The findings indicated that the satisfaction degree of families of children with special needs was medium. The dimensions of the questionnaire were arranged as the following: physical well-being and availability of tools, family interaction, parenting, support related to disability and emotional wellbeing. Among the recommendations of the research: Conducting more Arabic studies to measure the physical, moral and psychological needs of families of children with special needs.
\end{abstract}

Keywords: Quality of Family Services, Special needs, Early intervention

\section{INTRODUCTION}

The development of the education sector of children with special needs in Jordan has witnessed major changes. The laws and legislations have emphasized the need for more attention and development in relation to this group of children and their families, according to the important role that early intervention programs play in the adjustment process for families of children with special needs, and reduction of material and moral consequences of these families as well as the importance of the early years of these children. Learning is easier and faster during these years. Kirk, Gallagher \& Tasiow (2013) defined early intervention as the wide range of services provided to young children, and their families, through pregnancy, breastfeeding and early childhood. Currently, the participation of the family in all programs of early intervention for children with special needs is one of the most important factors, in the growth and development of the child. It also has a role in the level of family life and in the success of the programs offered. The role of the family is not limited to raising the child only, but also to participate in making the necessary decisions about the nature of different services (Brown, Rillotta, \& Samuel, 2012)

This study came to measure the satisfaction of families of children with special needs about the quality of early intervention services, in particular the family services that these families receive from specialized centers, professionals and specialists. These services include support, awareness and guidance as well as material services, which provide these families with the necessary equipment and support materials for the growth of the special need child and his development.

By reviewing previous studies, the family quality of life (FQOL) measure has been employed (Wang \&Brown, 2009 ;chiu, chen, chou \& Chien, 2017). This measure aims at increasing the family's acceptance of disability as well as forms a kind of adaptation to its child's disability, and thus the desire to obtain family services. 
By reviewing the dimensions of the family quality of life measure (Gardiner \& Laroci,2015) . It appears that the services included in these dimensions are services centered around the family of the disabled child. These dimensions are derived from the fact that the family and not the professionals are the forces that influence the child's life. The family of the child with special need is more aware of the needs and requirements of the child, as well as the fact that the child's family is one of the best which provide the necessary assistance to the child which requires service providers to show some understanding of what families need from services and information. In addition, studies have shown that the involvement of families of children in the decision-making process on the quality of family services provided to them and their children provides them with the appropriate appreciation, and works to improve and develop the follow up procedures for services provided (Chiu, et al, 2017; Wang \& Brown , 2009 ;Junst , 2002 ; Juwa , Welld \& Lalinde , 1993)

Recent studies and research have shown that the nature of the professionals and families of children with special needs have changed. It is no longer the role of professionals, as in the past, to provide explanations about the child's special needs to parents, and provide them with the necessary instructions and training to care for children with special needs and provide appropriate treatment. The mother is no longer communicating with the professionals, while the role of the rest of the family is little in this area. But studies have shown that, in the present, there has been a change in the nature of communication to include the participation of all members of the family.

Despite the fact that all families share many characteristics, however, each family has a degree of exclusivity in terms of the degree of satisfaction or dissatisfaction with the quality of family services. Therefore, when providing services to these families, professionals should take into consideration two dimensions related to the quality of family services: The dimension that families share globally, and the dimension that the family is unique in giving it the specific value and according to what it deems appropriate and necessary for the family and its child. The last dimension is the most important as professionals and researchers tend to respect the family and its wishes and what is considered important to it (Parish, Pomeranz, Hemp, Rizzola \& Braddock, 2001; Brown, Anand, Fung, Issaces \& Baum, 2003; Turnbull \& Turnbull , 2004 ; Duwa, Wells, \& Lalinde, 1993; Dunst, 2002; Lanners \& Mombaerts, 2000).

Bailay, Scarborough \& Hebbeler (2003) conducted a study on parents to assess their satisfaction with early intervention programs in America. The findings indicated that $75 \%$ of the responses, confirmed that they received the right amount of services, and $61 \%$ confirmed the degree to which their child therapists had experience and knowledge. They were described as distinguished, and 99\% had good feelings about the professional services provided to them. In a study conducted by Wang, Summers, Little, Turnbull, Poston \& Mamron (2006) to measure the approximation of the responses of fathers and mothers on the dimensions of the scale of the quality of family services, and those with children with disabilities from the age of birth to five years, and are subject to early intervention program. The findings showed that the responses of the fathers and mothers are close to the dimensions of the quality measure of family services.

Ganemo, Svensson, Lindbers \& Wahlgren, (2007) carried out a study to find out the impact of children with breathing difficulties on the quality of families life from which they come, by finding that the injury of American children has affected children and their families by their answers on the scale (FQOL) and the dimensions it contains. The findings provided information on the importance of understanding the condition of patients with eczema and 
their families. The findings showed that the severity of the problems experienced by the children affected their families' responses tothe family life quality measure.

Summers, et al., (2007) conducted a study to measure the satisfaction of young children families regarding the perceived adequacy services, in Mid Western State. Three family measures were applied. The findings indicated that the families of children were satisfied about their children's services and dissatisfied with the services they provided with as families. The findings also clarified that the children families found the level of the relationship with service providers was appropriate, but not convinced that service providers have the potential to meet the individual needs of their children, and to provide them with information about the services. Respondents also showed satisfaction with the quality of family entertainment, but their responses showed little assessment for the quality of emotional family life on (FQOL) scale.

Davis \& Gavida (2009) carried out a study to discover the impact of child, family and professional support characteristics on the quality of life in the families of young children with disabilities. The sample consisted of (64) families of children aged from 3-5 years, suffer developmental delay or disability. The findings indicated that parents perceptions of professional support centered around the family on (FQOL) scale were one of the strongest factors predicting the quality of family life.

Fei,Wang,\& Hu,(2012) conducted a study to discover the perceptions of Chinese families with children with mental disabilities about the quality of family life they receive as families. The sample consisted of (442) families. The study showed similar findings comparing with the families that live in America. The study also showed that the type of mental disability unit with the level of the family income was one of the signals that indicate the satisfaction rates of these families.

Gardiner \& Larocci (2015) carried out a study to test the role of the characteristics of autistic child in terms of behavioral problems and functional adjustment to the family and linking their relationship to the measure of the quality of family life. The sample consisted of (484) of the families of children and adolescents with special needs and between the ages of 6 to 18 years. The findings showed the degree of satisfaction among families, with regard to age, sex, disability unit, behavioral problems and family income variables.

Finally Brown, Schmidt, \& Schmidt (2017) conducted a study aimed at providing information on the quality of life of families of disabled children and developmental delays in early intervention programs in Slovenia, and families of children suffering from autism disorder. The findings indicated that family relations were a powerful factor in the family life quality measure, and that the families that showed strength on this side were characterized by their support for each other and bear the burden of disability and steadfastness in the face of problems and have high level of confidence.

\section{Research Problem and its questions}

The current research problem emerged through the identification of the quality of family life in light of variables related to the measure of quality of family life. The problem summarized by answering the following two questions:

1. What is the degree of satisfaction of families of children with special needs about the quality of services provided to them in early intervention centers in Jordanian governorates? 
2. What is the degree of satisfaction of families of children with special needs about the quality of services provided to them according to the five dimensions: family interaction, parenting, support related to disability, physical well-being and availability of tools, and emotional well-being?

\section{The importance of the research}

This research attempted to identify the degree of satisfaction of families of children with special needs about the quality of family services available in early intervention centers in Jordanian governorates. The importance of the current research is illustrated by the following points:

1. To verify the relationship between the parents' perceptions and their experiences with the care provided by professionals, the services provided to the family and the quality of the family life.

2. Identifying parents' views on what is important for families, so that their lives are good for each other, through identifying the standard parts of the quality of life.

3. Identifying the quality of family life, empower researchers to visualize how and where to provide the support needed for families, and when it constitute assistance to the family, and can also be used in the documentation of the progress resulting from the employment of family support programs.

\section{Limitations of the research}

This research is restricted on families of children with special needs in early intervention centers in Amman, Irbid and Karak governorates for ages 3-5 for the year 2016.

\section{Definition of terms}

Family life quality scale: This concept relates to the quality of family life. It measures family perceptions about the importance of different dimensions of the quality of family life, as well as, to measure the degree of their conviction in the quality of family life. The scale consists of five main dimensions: family interaction, parenting, support related to disability, physical wellbeing and availability of tools and emotional well-being.

Families of children with special needs: they are intended for fathers and mothers of children with special needs.

The operational definition of family life quality scale is the degree to which fathers and mothers of children with special needs have obtained on the different dimensions of the quality of family life.

\section{METHOD}

The methodology of the research included the methodology used, population of the research, the sample, the instrument, and statistical tools, as follows:

\section{Participants}

The population of the research consisted of all families of children with special needs, aged 3 to 5 and enrolled in early intervention centers in the various governorates of the kingdom.

\section{Sample}

The sample of the research consisted of (100) families, who drawn randomly from the population by using simple random sample method. 


\section{Research methodology}

The descriptive-survey methodology was used, to achieve the objectives of the research. The questionnaire was used to collect the data of the research.

\section{Instrument}

The family quality of life scale has been translated. It included five main dimensions: family interaction, parenting, support related to disability, physical well-being and availability of tools and emotional well-being.

\section{Validity and reliability}

The validity of the instrument has been confirmed by presenting it to a jury from teaching staff members of Jordanian universities.

The reliability of the instrument has been confirmed by calculating the internal consistency by using Cronbach-Alpha formula. The value was (0.82). This value is acceptable. Table 1 . shows reliability values of the dimensions of the instrument

Table 1. Reliability coefficients of the family life quality scale according to its dimensions.

\begin{tabular}{|l|l|l|}
\hline No. & Dimension & Cronbach-Alpha \\
\hline 1. & Family interaction & 0.84 \\
\hline 2. & Parenting & 0.77 \\
\hline 3. & Support related to disability & 0.79 \\
\hline 4. & Physical well-being and availability of tools & 0.90 \\
\hline 5. & Emotional well-being & 0.81 \\
\hline & Total score & 0.82 \\
\hline
\end{tabular}

\section{Procedure}

The questionnaire was sent to the sample subjects of the families of children with special needs, mediated by teachers in the centers of early intervention. Teachers visited families in their homes in the governorates of Amman, Al-Karak and Irbid. Teachers provided the families with questionnaire and asked them to return it with the teachers to ensure the confidentiality of the information.

\section{Statistical methods}

The statistical methods employed to analyze data, included: means, standard deviations, ranks and the degrees of satisfaction.

\section{Results}

This part of the research included the findings through answering the questions and their discussion as follows:

First: What is the degree of satisfaction of families of children with special needs about the quality of services provided to them in early intervention centers in Jordanian governorates? To answer this question, means, standard deviations and ranks were used as well as the degree of satisfaction of the families, as clarified in table 2 . 
Table 2. Means, standard deviations, ranks and the degree of satisfaction of families of children with special needs about the services provided to them in the Jordanian governorates

\begin{tabular}{|l|l|l|l|l|l|}
\hline No. & Dimension & Mean & $\begin{array}{l}\text { Standard } \\
\text { deviation }\end{array}$ & Rank & $\begin{array}{l}\text { Satisfaction } \\
\text { degree }\end{array}$ \\
\hline 4. & $\begin{array}{l}\text { Physical well-being and availability of } \\
\text { tools }\end{array}$ & 2.29 & 0.34 & 1 & Medium \\
\hline 1. & Family interaction & 2.27 & 0.46 & 2 & Medium \\
\hline 2. & Parenting & 2.25 & 0.39 & 3 & Medium \\
\hline 5. & Support related to disability & 2.22 & 0.52 & 4 & Medium \\
\hline 3. & Emotional well-being & 1.92 & 0.39 & 5 & Medium \\
\hline & Total score & 2.20 & 0.31 & - & Medium \\
\hline
\end{tabular}

It is noted from the table 2. that the degree of satisfaction of families of children with special needs for the services provided to them was medium. The mean was (2.20) with a standard deviation of (0.31). The dimensions of the research tool came in the middle degree with the means of (2.29-1.92). Physical-well-being and availability of tools dimension came in the first rank. Its mean was (2.29) and standard deviation of (0.34). Family interaction dimension came in the second rank. Its mean was (2.27) and standard deviation of (0.46).

Support related to disability dimension came in the pre-final rank. Its mean was (2.22) with a standard deviation of (0.52). Emotional well-being dimension came in the final rank with a mean of (1.92) and standard deviation of (0.39).

Second: What is the degree of satisfaction of families of childrenwith special needs about the quality of services provided to them according to the five dimensions: Family interaction, parenting, support related to disability, physical well-being and availability of tools, and emotional well-being?

This question has been answered according to its dimensions as follows:

Physical well-being and availability of tools: Means, standard deviations, ranks and the degree of satisfaction of families were used, as clarified in table 3.

Table 3. Means, standard deviations, ranks and satisfaction degree of families of children with special needs about the quality of services provided to them in the dimension of "Physical wellbeing and availability of tools", in descending order

\begin{tabular}{|l|l|l|l|l|l|}
\hline No. & Item & Mean & S.D. & Rank & Satisfaction degree \\
\hline 17 & My family receives dental care when needed & 2.39 & 0.72 & 1 & Medium \\
\hline 20 & $\begin{array}{l}\text { My family feels save at home, work, school and } \\
\text { the neighborhood }\end{array}$ & 2.35 & 0.63 & 2 & Medium \\
\hline 16 & $\begin{array}{l}\text { My family members have the transportation to } \\
\text { reach the places they need access to }\end{array}$ & 2.27 & 0.69 & 3 & Medium \\
\hline 18 & My family receives medical care when needed & 2.24 & 0.71 & 4 & Medium \\
\hline 19 & $\begin{array}{l}\text { My family has a way of taking care of the } \\
\text { material expenses }\end{array}$ & 2.20 & 0.68 & 5 & Medium \\
\hline & Total score & 2.29 & 0.34 & - & Medium \\
\hline
\end{tabular}

It is noted from table 3. that the satisfaction degree of the families of children with special needs about the services provided to them in the "physical well-being and availability of tools" dimension was medium. Its mean was (2.29) with a standard deviation of (0.34). All items came in the middle degree, and their mean scores were between (2.39-2.20). 
Item (17) that states "My family receives dental care when needed" came in the first rank with a mean of (2.39) and standard deviation of (0.72). While item (19) that states "My family has a way of taking care of the material expenses" came in the last rank, with a mean of (2.20) and a standard deviation of (0.68).

\section{Family interaction dimension.}

Means, standard deviation, ranks and satisfaction degree of the families of children with special needs about the quality of services provided to them in "family interaction" dimension, were used as clarified in table 4.

Table 4. Means, standard deviation, ranks and satisfaction degree of the families of children with special needs about the quality of services provided to them in "family interaction" dimension in descending order.

\begin{tabular}{|l|l|l|l|l|l|}
\hline No. & Item & Mean & S.D. & Rank & $\begin{array}{l}\text { Satisfaction } \\
\text { degree }\end{array}$ \\
\hline 3 & $\begin{array}{l}\text { My family members solve their problems with } \\
\text { each other }\end{array}$ & 2.48 & 0.70 & 1 & Medium \\
\hline 2 & My family members talk to each other openly & 2.39 & 0.57 & 2 & Medium \\
\hline 5 & My family members seem to love each other & 2.23 & 0.71 & 3 & Medium \\
\hline 4 & $\begin{array}{l}\text { My family members support each other to } \\
\text { achieve their goals }\end{array}$ & 2.21 & 0.77 & 4 & Medium \\
\hline 1 & My family likes to spend time with each other & 2.04 & 0.80 & 5 & Medium \\
\hline & Total score & 2.27 & 0.46 & - & Medium \\
\hline
\end{tabular}

As shown in table (4) that the satisfaction degree of families of children with special needs about the services provided to them was medium with regard to "family interaction" dimension. Its mean was (2.27) with a standard deviation of (0.46). All items came in the middle degree, and their mean scores ranged from (2.48) to (2.04). Item (3) that states "My family members solve their problems with each other" came in the first rank, with a mean of (2.48) and a standard deviation of (0.70).While item (1) that states "My family likes to spend time with each other" came in the last rank, with a mean of (2.04) and a standard deviation of (0.80).

\section{Parenting dimension}

Means, standard deviations, ranks, and satisfaction degree of families of children with special needs about the quality of services provided to them in "Parenting" dimension, were used as clarified in table 5 . 
Table 5. Means, standard deviations, ranks, and satisfaction degree of families of children with special needs about the quality of services provided to them in "Parenting" dimension in descending order

\begin{tabular}{|l|l|l|l|l|l|}
\hline No. & Items & Mean & S.D. & Rank & $\begin{array}{l}\text { Satisfaction } \\
\text { degree }\end{array}$ \\
\hline 9 & $\begin{array}{l}\text { Adults in my family teach children with special } \\
\text { needs how to make good decisions }\end{array}$ & 2.40 & 0.65 & 1 & Medium \\
\hline 11 & $\begin{array}{l}\text { Adults in my family have the time to take care of the } \\
\text { individual needs of each child }\end{array}$ & 2.35 & 0.70 & 2 & Medium \\
\hline 6 & $\begin{array}{l}\text { My family members can deal with happy and sad } \\
\text { situations }\end{array}$ & 2.29 & 0.64 & 3 & Medium \\
\hline 10 & $\begin{array}{l}\text { Adults in my family know the others in the life of the } \\
\text { child with special needs, such as their teachers and } \\
\text { friends }\end{array}$ & 2.28 & 0.70 & 4 & Medium \\
\hline 7 & $\begin{array}{l}\text { My family members help children with special } \\
\text { needs to learn to become more independent }\end{array}$ & 2.14 & 0.70 & 5 & Medium \\
\hline 8 & $\begin{array}{l}\text { My family members help children with special } \\
\text { needs to learn how to communicate with others }\end{array}$ & 2.04 & 0.74 & 6 & Medium \\
\hline & \begin{tabular}{l} 
Total score \\
\hline
\end{tabular} & 2.25 & 0.39 & - & Medium \\
\hline
\end{tabular}

Table 5, shows that the satisfaction degree of families of children with special needs about the services provided to them was medium in "Parting" dimension. The mean was (2.25) with a standard deviation of (0.39). All items came in the middle degree, and their mean scores ranged from (2.40) to (2.04). Item (9) that states" Adults in my family teach children with special needs how to make good decisions "came in the first rank. Its mean was (2.40) with a standard deviation of (0.65). While item (8) that states "My family members help children with special needs to learn how to communicate with others", came in the last rank, with a mean of (2.04) and a standard deviation of (0.74).

\section{Support related to disability dimension.}

Means, standard deviations, ranks and satisfaction degree of families of children with special needs about the quality of services provided to them in "Support related to disability" dimension were used as clarified in table 6. 
Table 6. Means, standard deviations, ranks and satisfaction degree of families of childrenwith special needs about the quality of services provided to them in "Support related to disability" dimension in descending order

\begin{tabular}{|l|l|l|l|l|l|}
\hline No. & Items & Mean & S.D & Rank & $\begin{array}{l}\text { Satisfaction } \\
\text { degree }\end{array}$ \\
\hline 24. & $\begin{array}{l}\text { My family members have good relationships } \\
\text { with people who provide them with service } \\
\text { o a family member with a disability }\end{array}$ & 2.27 & 0.71 & 1 & Medium \\
\hline 21. & $\begin{array}{l}\text { My family members with special needs have } \\
\text { support for progress in school or work }\end{array}$ & 2.23 & 0.68 & 2 & Medium \\
\hline 22. & $\begin{array}{l}\text { My family members with special needs have } \\
\text { support for progress at home }\end{array}$ & 2.20 & 0.75 & 3 & Medium \\
\hline 23. & $\begin{array}{l}\text { My family members with special needs have } \\
\text { support to form friends }\end{array}$ & 2.18 & 0.77 & 4 & Medium \\
\hline & Total score & 2.22 & 0.52 & - & Medium \\
\hline
\end{tabular}

Table 6, shows the satisfaction degree of families of children with special needs about the services provided to them was medium in "Support related disability "dimension.The mean was (2.22) with a standard deviation of (0.52). All items came in the middle degree, and their mean scores ranged from (2.27) to (2.18). Item (24) states that "My family members have good relationships with people who provide them with service to a family member with a disability", came in the first rank. It mean was (2.27) with a standard deviation of (0.71). While item (23) that states "My family members with special needs have support to form friends", with a mean of (2.18) and a standard deviation of (0.77).

\section{Emotional well-being dimension}

Means, standard deviations, ranks and satisfaction degree of families of children with special needs about the quality of services provided to them in "Emotional well-being" dimension were used as shown in table 7.

Table 7. Means, standard deviations, ranks and satisfaction degree of families of children with special needs about the quality of services provided to them in "Emotional well-being" dimension in descending order

\begin{tabular}{|l|l|l|l|l|l|}
\hline No. & Items & Mean & S.D. & Rank & $\begin{array}{l}\text { Satisfaction } \\
\text { degree }\end{array}$ \\
\hline 14. & $\begin{array}{l}\text { Some members of my family have time to work } \\
\text { on their own interests }\end{array}$ & 2.18 & 0.73 & 1 & Medium \\
\hline 15. & $\begin{array}{l}\text { My family members have external help to care } \\
\text { for all members of the family }\end{array}$ & 2.10 & 0.72 & 2 & Medium \\
\hline 13. & $\begin{array}{l}\text { My family members have friends and other } \\
\text { individual who provide the support they need }\end{array}$ & 1.87 & 0.49 & 3 & Medium \\
\hline 12. & $\begin{array}{l}\text { Enough support is available for my family to } \\
\text { accept stress. }\end{array}$ & 1.54 & 0.64 & 4 & Medium \\
\hline & Total score & 1.92 & 0.39 & - & Medium \\
\hline
\end{tabular}

Table 7, illustrates that the satisfaction degree of families of children with special needs about the services provided to them was medium in "Emotional well-being" dimension. The mean was (1.92) with a standard deviation of (0.39). All items came in the middle degree, and their mean scores ranged from (2.18) to (1.54). Item (14) states that "Some members of my family have time to work on their own interests", came in the first rank with a mean of (2.18) and a standard deviation of (0.73). While item (12) states that "Enough support is available for my 
family to accept stress" came in the last rank. Its mean was (1.54) with a standard deviation of (0.64).

\section{DISCUSSION}

First: Discussion of the findings of question one: This finding is in line with the findings of several global studies, such as: Brown, etal. (2017), Gavida \& Davis, 2009, Fei, etal, 2012, Summers, etal, 2007. Which showed that the degree of satisfaction of the families was moderate in relation to "physical well-being and availability of tools" dimension. The side of family interaction and family relationships are a powerful factor in the family quality of life scale.

Family relations dimension provides researchers with a kind of optimism with regard to the status of these families. In spite of the difficulties and psychological stress in encountering the daily life and its requirements as a result of parental care for the disabled child, it can be concluded that families whose answers were high in this dimension, that they share some characteristics and are mutually supportive. These families are resilient to the challenges. And have mutual trust among family members. Family services in early intervention centers in Jordan concentrate on providing basic services that are related to physical well-being and availability of tools, and support services for the family, and not focus on emotional well-being. So this dimension came in the final rank in this research.

Second: The discussion of the findings of question two according to the dimensions:

1. Physical well-being and availability of tools dimension: The satisfaction degree of families of children with special needs in this dimension was medium. This finding may be attri buted to the family that doesn't receive dental care or safety services for children in sch ool or neighborhood, or medical services may be needed by the Jordanian family. The $m$ ain reason may be attributed to the difficulty faced by these families in obtaining the su pport and services required. This finding may indicate that many of the services needed by these families are not available, as well as the lack of information available to them $b$ $\mathrm{y}$ those responsible for providing these services. The needs of Jordanian families that ca re for children with special needs are constantly changing, which requires a kind of plan ning and preparation for these families inside the house, and in early intervention cente rs. This may also be due to the apparent lack of professionals and specialists who are abl e to deal with disabled children and their families. This finding was agreed with the stud ies of Summers, et al., (2007) and Davis \& Gavidia,(2009), and contradict with the findin gs of the study conducted by Bailay, et al., (2003).

2. Family interaction dimension

The satisfaction degree of families of children with special needs in this dimension was medium. The responses of both mother and father were close on the quality of family life scale, and were close with the findings of Wang, et al., (2006) and Summers, et al., (2007).

3. Parenting dimension

The satisfaction degree of families of children with special needs in this dimension was medium. The families of children with special need have not been subject to training, guidance, to help their adults' sons and daughters how to care for disabled children. Brothers feel ashamed of their disabled siblings and try to avoid involve him in social activities. Family isolation and anxiety about disability and its consequences and partial or total absence to support from relatives, neighbors and friends affect these families, because of their lack of knowledge and discomfort during their work with children with disabilities. This finding was agreed with Brown's study (2012).

4. Support related to disability dimension: 
This satisfaction degree of families of children with special needs in this dimension was medium. This finding may be attributed to the relationship of families with special needs with service providers which depends, primarily, on receiving assistance that includes supporting devices and tools. Sometimes a poor relationship constitutes when service providers cannot provide these devices and tools for the family. This finding may be attributed to the providers who do not provide appropriate support for the family to follow the care of children at home, and their services are limited to the services in the centers only, as well as, service providers don't provide support to families to help them get to know each other and establish friendly relationships that are beneficial to them. This finding was agreed with the findings of the study conducted by Summers, et al., (2007).

5. Emotional well-being dimension:

The satisfaction degree of families of children with special needs in this dimension was medium. This finding may be attributed to the fact that these families are deprived of this dimension because, it does not included in family service plans alleviating the psychological pressures that may be caused by recreational activities for family members. Parents are busy providing basic requirements permanently, that exhausted psychologically, comparing with countries that are interested in meeting the needs of families in terms of emotional and emotional aspects. The families do not have enough time to do their own jobs or even devote themselves because they do not receive sufficient support to help them cope with the burden of having a disabled child as well as, these families have not been trained in family guidance and counseling to help them tolerate stress, as a result of a disabled child. This finding is agreed with Jackson, et al., (2010)study

\section{CONCLUSION}

In light of the findings, the researcher recommends the following:

1. Conducting more Arabic studies to measure the physical, moral and psychological needs of families of children with special needs.

3. Providing more information necessary to measure the quality of family life for the families of individuals with special needs, especially, the mentally disabled, children of autism and the late development for researchers, professionals and decision-makers in Jordan.

3. Inform specialists and professionals to employ the family life quality measure in planning and developing family-based intervention plans.

4. Employing family life quality measure to evaluate and measure the effectiveness of family support services.

\section{References:}

Bailey,D.,\&Scarborough, A., \& Hebbeler, K. (2003).Families 'First Experiences with early Intervention. Menlo Park, Ca: Sri International.

Brown.I,.Anand.S, Fung,. W,Issacs.B,. Baum, N. (2003). Family quality of life. Canadian results from an international study, Journal of Developmental and Physical Disabilities, 15,207-230.

Brown, I. (2012). Family quality of life: 18 Studies In 14 Countries. Paper Presented At IASSIDD World Congress, Halifax, Canada, July 9-14

Brown, I,. Schmidt., J,. \&Schmidt.M.(2017).Quality of Life Among Families of Children With Intellectual Disabilities Slovene Study, Journal of Intellectual Disabilities Research, 14(1),87-102

Chiu.S,. Chen.P,. Chou.Y,. \&Chien.L . (2017). Center Family Quality of Life Scale: development and psychometric properties in Taiwanese families of children with development delay. Journal of Intellectual Disability Research.61(4),373-384. 
Davis.K,. \&Gavidia,S.(2009).The Impact of Child, Family, And Professional Support Characteristics on The Quality of Life In Families of Young Children With Disabilities, Journal of Intellectual \&Developmental Disability,34 (2),P153-162.

Duwa, S. M,. Wells, C.,\&,. Lalinde, P.(1993). Creating family- centered programs and policies. In D.M.Bryant \&M.A.Grham (Eds.), Implementing early intervention: From research to effective practices (pp.92-123) New York:Guilford Press.

Dunst,C.J.(2002). Family-Centered Practices: Birth through High School. The Journal of Education, 36(32). Fei.X,.Wang.M,. Hu.X.(2012).Family quality of life of Chinese families of children with intellectual disabilities. Journal of Intellectual Disabilities Research, 56(1),122-133.

Gardiner. E,. \&Laroci.G. (2015). Family Quality of Life and Asd:The Role of Child Adaptive Functioning and Behavior Problems. Journal of Intellectual Disabilities Reasearch,8(2),199-213.

Summers,J.,Marquis,J.,Mannan,H.,Turnbull,A.,Fleming,K.,Poston,D.,Wang,M.,\&Kupzy,K.(2007).Relationship of Perceived Adequacy of Services, Family-Professional Partnerships and Family Quality of Life In Early Childhood Service Programmes. International Journal of Disability, Development\& Education, 54(3), 319-338.

Turnbull, A.P.,Brown, I.,\&Turnbull, R.H., III (Eds). (2004) Families and Persons with Mental Retardation and Quality of Life: International Perspectives.Washington,DC:American Association on Mental Retardation.

Wang,M,.\&Brown,R.(2009).Family Quality of Life: A Framework for Policy And Social Service Provisions To Support Families of Children with Disabilities . Journal of Family Social Work, 12:144-167.

Wang.M,.Summers.J,.Little.T,.Turnbull.A,.Poston.D,.Mamron.H.(2006).Perspectives of fathers and mothers of children in early intervention programs in assessing family quality of life. Journal of Intellectual Disabilities Research, 50(12), 977-988. 